\title{
Framing Effects, Procedural Fairness, and the Nonprofit Managers' Reactions to Job Layoffs in Response to the Economic Shock of the COVID-19 Crisis
}

\author{
Min-Hyu $\operatorname{Kim}^{1}$ (D)
}

Accepted: 22 November 2021 / Published online: 9 January 2022

(c) International Society for Third-Sector Research 2021

\begin{abstract}
The COVID-19 pandemic has challenged the viability and effectiveness of nonprofit organizations compelling them to make tough choices. Evidence suggests that different wordings or message settings may affect people's decisions when presenting equivalent outcome information with positive or negative framing. Nevertheless, there have been few attempts to assess how procedural fairness and framing effects shape nonprofit managers' reactions to job layoffs due to the COVID-19 pandemic. Using a survey experiment, we explore whether framing effects—by affecting perceived outcome favorability—and procedural fairness interact to influence nonprofit managers' trust and support for their organizations. The findings of this $2 \times 2$ between-participants experimental design indicated that only when procedural fairness was relatively low did nonprofit managers react more favorably in the positive frame (keep) than in the negative frame (layoff) condition. This study adds to our understanding of how the pandemic impacts nonprofit managers, including their commitment to continue working in the sector, and has practical implications for nonprofit organizations that manage resilience in a crisis.
\end{abstract}

Keywords Framing effects · Procedural fairness · COVID19 - Layoff · Trust

Min-Hyu Kim

mkim2021@dongguk.edu

1 Department of Public Administration, Dongguk UniversitySeoul, 04620 Seoul, South Korea

\section{Introduction}

The layoffs in United States (hereafter U.S.) nonprofit organizations have been particularly challenging since 2020 due to COVID-19, and nonprofit employees expect more of the same in 2021. For example, between March and May 2020, nonprofit organizations across the U.S. had a total of $1,643,128$ job losses, as follows: 14,689 in professional, scientific, and technical services, 323,201 in educational services, 574,530 healthcare, 259,007 social assistance, 205,964 arts, entertainment, and recreation, 218,167 other services (except public administration), and 47,450 in other fields (Salamon \& Newhouse, 2020). ${ }^{1}$ Further, according to a survey conducted by Eagle Hill Consulting (2021), 20\% of nonprofit employees said their employers implemented layoffs in 2020, and 49\% expect more cuts in 2021. These estimates are worrisome because the COVID-19 pandemic resulted in many nonprofit organizations experiencing greater demand while canceling vital fundraising events due to strong social distancing measures (Courtemanche et al., 2020).

Previous literature on procedural fairness suggests that perceived outcome favorability and procedural fairness interactively influence the managers' reactions to job layoffs (Colquitt, 2001; Cropanzano, Byrne, Bobocel, \& Rupp, 2001; Moorman, 1991). ${ }^{2}$ There have been some

\footnotetext{
${ }^{1}$ Other services (except public administration) include religious, grantmaking, civic, professional, and similar services, while other fields encompass homeless shelters and food banks (Salamon \& Newhouse, 2020).

${ }^{2}$ With respect to the difference between procedural fairness and procedural justice, procedural fairness concerns the inclusion and respectful treatment of relevant stakeholders in a decision-making process, while procedural justice posits that individuals' responses to decisions are influenced by "the fairness of the decision-making procedures" (Tyler, 1991, p. 261).
} 
successful attempts to improve the remaining employees' reactions to job layoffs in the for-profit sector (Brockner, 1992; Brockner et al., 1995), ${ }^{3}$ but an empirical evaluation of whether this holds in nonprofit organizations is missing. This gap in the literature is problematic given the efforts of nonprofit organizations worldwide to make themselves more resilient in various, often innovative ways to ameliorate the shocks associated with crises such as pandemics. More research is required to develop preventive and coping strategies to enhance nonprofit managers' reactions to job layoffs in response to the economic shock of the COVID19 pandemic.

The negative economic aspects of the COVID-19 pandemic affect nonprofit managers' trust and support for the organization (The NonProfit Times, 2020). When recovery of pandemic-related job losses is slow in the nonprofit sector, it leads to managers' erosion of trust and support in the organization with ensuing management difficulties. In this regard, prospect theory suggests that managers evaluate decision outcomes differently when presented with matching criteria with either a procedurally fair or unfair framing. Generally, framing effects mean that the presentation method of a decision problem influences how people summarize and ultimately act upon the problem (Chong \& Druckman, 2007). Brockner et al. (1995) found that the interaction between decision frame and procedural fairness influences remaining employees' trust and support for the for-profit organization. In Brockner et al.'s (1995) study, the effect of decision frames (positive or negative) on organizational trust and support in the private sector is statistically significant only when it is procedurally unfair. In other words, employees had less confidence in their organization due to job layoffs, only when the procedure was unfair. Of interest to this study is whether nonprofit managers also suffer from this framing effect. Addressing this problem will give nonprofit managers the insight to adjust their policy and strategies, ensuring that managers receive the support they need and deserve, contributing to a more nuanced understanding of the behavioral aspect of the prospect theory for nonprofit organizations.

This research investigated effective strategies to help the nonprofit workforce cope with the pressures suffered by its members. We conducted experiments to measure the effect of job layoffs on trust and support contingent upon the

\footnotetext{
3 Brockner et al.'s (1995) study uses the term "survivors" instead of the expression "remaining employees" or "managers." In other words, business administration studies on the response to layoff uses the term "survivors" without distinguishing managers from employees. Given that this study is particularly about whether nonprofit managers are susceptible to framing effects, we selected nonprofit leaders as the respondents.
}

fairness of decision-making procedures. Building on previous literature in prospect theory, we replicated Brockner et al.'s (1995) study to investigate how to minimize the inevitable side effects of layoffs in U.S. nonprofit organizations during the COVID-19 pandemic. ${ }^{4}$ Brockner et al.'s (1995) study showed multiple determinants of employees' reactions to job layoffs: a negatively framed decision should matter to a greater extent in procedural unfairness contexts. Under such conditions, decision frame influences employees' beliefs about improvements in their career opportunities and should affect their trust and support for the organization. Our conceptual replication examined framing effects on nonprofit managers' trust and support in an economic downturn battering nonprofit organizations with ensuing layoffs because of the COVID-19 pandemic.

This study selected nonprofit executives as its research subjects for the following three reasons. First, we selected nonprofit executives as respondents because this study is about whether nonprofit managers are susceptible to framing effects. Second, nonprofit executives are in charge of most of the day-to-day management of their organization and are likely to be most familiar with important issues related to the organization, not to mention that they exert substantial influence on key decision-making processes (Ingram, 2019). Lastly, designing transparent decisionmaking processes and institutionalizing regulations to ensure accountability and responsibility for nonprofit managers' decisions is challenging in nonprofit management for the post-COVID-19 era (Delronge et al., 2019).

\section{Equivalence Framing and Managerial Assessment of Procedural Fairness}

A core insight from prospect theory demonstrates that responses to information depend on whether the information is negatively or positively framed (Tversky \& Kahneman, 1981, 1992). The effects are attributed to information frames resulting from a cognitive bias, meaning that individuals do not carefully evaluate the

\footnotetext{
$\overline{4}$ With respect to the inevitable side effects of layoffs, layoffs decrease the work-related motivation and attitudes of the remaining employees, and it has a negative effect on organizational performance (Brockner, 1992; Brockner \& Greenberg, 1990). The reactions and behaviors of people who survived massive and adverse events, such as the 2008 Recession, showed that layoffs caused workers to experience increased feelings of remorse and develop more negative attitudes toward their organizations. Researchers found various forms among employees who blame themselves for doing too little to help these laid-off employees, who may feel a form of guilt in the face of their colleagues' suffering.
} 
information to which they are exposed. The main takeaway from this research is that framing can influence managers' decision-making.

Applying prospect theory to the nonprofit sector, we see that the prospects of gains and losses drive the day-to-day decisions made by nonprofit organizations and their managers (Kahneman \& Tversky, 1979). Based on prospect theory, framing effects can transform an individual's point of reference for judging whether perceived information is a benefit or harm to some individual or organization by framing the information in a positive or negative light (Schelling, 1984). That is, if you present probabilistically equivalent information in a positive light, its interpretation will be different than if giving it in a negative light (Kahneman \& Tversky, 1979). This notion of equivalency framing has been expanded and adopted in experimental research to examine the behavioral aspect of nonprofit organizations.

The literature on nonprofit organizations includes the effect of framing effects on charitable giving. For example, Chang (2008) argued that when the price of a product is low, the donation amount in absolute U.S. dollars is more effective than in percentage terms. Furthermore, Chang and Lee (2009) indicated that donation advertisements are more effective when sending negative pictures and negative messages. Similarly, Zolner et al. (2010) show that it is effective for nonprofit organizations to frame solicitation as a donation when the amount of the donation is small. In a more recent study, Qu and Daniel (2021) investigated the framing effects of nonprofit organizations' overhead on donor decisions.

These studies have contributed to our understanding of donors' behaviors. However, gaps in the previous literature remain regarding the behavior of nonprofit managers when a job layoff is inevitable due to the negative economic prospects of COVID-19. While there is heavy debate on the effects of the COVID-19 pandemic on human resource management in the private sector, ${ }^{5}$ it remains unclear how COVID-19 affects nonprofit human resource policies. For example, Young et al. (2020), using survey data in San

\footnotetext{
5 Generally, human resource management includes planning, acquisition, development, and sanctions (Klinger, Donald, \& Nalbandian, 2003). Regarding empirical studies on COVID-19's impact on human resources in the private sector, Mani and Mishra's (2020) extensive literature review found that during uncertain times, employee morale is low, and jobs are threatened as the economy suffers. Similarly, Terblanche (2021), using qualitative interviews with 26 executive coaches from the U.S., U.K., Australia, and South Africa during the first three weeks of April 2020, investigated how the COVID-19 pandemic initially affected organizational managers, from their executive coaches' perspectives. Using qualitative interviews with top and mid-level managers in a large food retail cooperative in Italy during late winter and spring 2020, Passetti, Battaglia, Bianchi, and Annessi (2021) found that administrative control mechanisms enabled an immediate response and management of reactions to COVID-19.
}

Diego nonprofits in March and April 2020, report that there has been a significant and unprecedented hollowing out of the nonprofit workforce, with $53 \%$ reporting staff furloughs, layoffs, reduced work hours, and reduced pay. Similarly, Kim and Mason (2020) found that nonprofits with more financial reserves are less likely to reduce operating hours, lose staff, or experience difficulty acquiring supplies or vendor services in response to the immediate impact of COVID-19 on human services and art nonprofits. However, today a more relevant question is just how procedural (un)fairness moderates the impact of decision frame on nonprofit managers' trust and support for the organization during the COVID-19 pandemic. Thus, our study builds on the available evidence and extends it to investigate sensemaking of COVID-19's impact on the sector's workforce.

\section{Defining Trust}

According to Greiling (2007), trust in the nonprofit sector has an internal (organizational) and external (environmental) perspective. However, the internal view-although no less important-has received considerably less attention than the external view. The internal perspective focuses on the dynamics of interpersonal trust within nonprofit organizations and has more recently garnered attention for its impact on overall organizational performance (Greiling, 2007; Knapp et al., 2019).

According to previous literature on trust in the nonprofit sector, trust comprises three major overlapping constructs: fairness, confidence, and risk-taking. Greiling's (2007) literature assessment notes that confidence and fairness are reliable attributes of trust. Nonprofit managers who consistently experience confidence and fairness within the organization and their relationships with their board of directors are exposed to trust as a measure of reciprocity, a notion grounded in social exchange theory (Knapp et al., 2019). Based on existing studies on trust in the nonprofit sector, the present analyses employ the following six statements measuring trust and support for the organization:

- The managers trust local ___ management.

- The managers are proud to tell others that they are a part of

- The managers' co-workers might have been quite mistrustful of top management since the beginning of the layoff. ${ }^{6}$

\footnotetext{
${ }^{6}$ For the third item, this study referred to Brockner et al.'s (1995) survey item on "My co-workers have been quite mistrustful of top management since the layoffs began" (reverse coded). With Cronbach's $\alpha$ for trust index at 0.95 even when the third item is removed in this study, we determined our trust index possesses a sufficient level of reliability.
} 
- Managers treat survivors fairly and consistently concerning HR.

- The managers trust management concerning HR decisions.

- The managers feel that they can trust the organization to treat them fairly.

The respondents answered on a five-point scale: 1 = Strongly disagree, 2 = Somewhat disagree, $3=$ Neither agree nor disagree, $4=$ Somewhat agree, and 5 = Strongly agree.

We explored whether U.S. nonprofit leaders are susceptible to framing effects when the decision-making procedures are unfair but less sensitive to framing effects when the process is fair. This potential reduction in bias from equivalence framing may be attributable to their professional experience in the nonprofit sector. For instance, Fuenzalida et al. (2020) found that civil servants are significantly more reflective and less susceptible to framing effects thanks to their professional experience. Further, Olsen (2015) found that citizens are less sensitive to framing effects depending on their current or previous work experience in the public sector. Thus, based on the available evidence, we offer the following hypothesis:

$\mathrm{H}$ : The effect of decision frame on nonprofit managers' trust and support for the organization is stronger in procedural unfairness contexts and weaker in procedural fairness contexts.

We drew upon the arguments of Yin (2003) on the merits of replication as a form of empirical generalization to build external validity across contexts (Piening, 2011; Zhu, 2014). In other words, we can determine the representativeness of the results of a previous study for a different sector by replicating Brockner et al.'s (1995) study with a different population. Replications compare findings across various subject groups to assess their degree of similarity and appropriateness for future research. While for-profit and nonprofit organizations are different in many ways, even down to the core of how and why they conduct business and operations, there are some similarities because they both do monetary transactions. For example, expectancy theory posits that for-profit employees act to maximize expected satisfaction with outcomes (Vroom, 1964). On the other hand, Lanfranchi et al. (2010) found that nonprofit employees had higher intrinsic work motivation than private workers because the nonprofit sector focuses on organizational missions, goals, stakeholders, and employee motivation. We posited that if the results of this study are similar to those of Brockner et al.'s (1995) study, researchers might expect that this study will produce stronger support for its empirical generalization in nonprofit organizations. If not, then this study will offer weaker results.

\section{Methods}

\section{$2 \times 2$ Between-Subjects Experimental Design}

We employed a 2 (framing effects: keep or layoff) $\times 2$ (procedural fairness: fair or unfair) between-subjects survey experiment to examine the proposed hypothesis (Fig. 1). First, we assigned respondents to one of four treatment groups following four types of hypothetical scenarios: 1) procedural fairness $\times$ keep condition, 2) procedural fairness $\times$ layoff condition, 3) procedural unfairness $\times$ keep condition, and 4) procedural unfairness $\times$ layoff condition. Then, respondents answered questions on the managers' trust and support for the organization. Figure 2 provides an overview of this design.

We distributed a survey to learn about the moderating role of procedural fairness on framing effects of nonprofit leaders across the U.S. We received responses from 403 participants between March and May 2020, including organizations based in all 50 states. The participants were nonprofit executives of various National Taxonomy of Exempt Entities (hereafter NTEE) subgroups. The sample consisted of 1,192 stratified random sampled nonprofit organizations from the National Center for Charitable Statistics (2013). Here, strata are made by randomly selecting $10 \%$ of the organizations from each defined group. A self-administered survey required obtaining email addresses for the selected 501(c)(3) organizations' executive directors, which we accomplished by visiting each nonprofit's webpage. We received Institutional Review Board (IRB) approval for the surveys used in this study, including the participant questionnaire and consent form (IRB ID: STUDY00010762).

Using $G^{*}$ Power software, we determined the sample size based on an a priori power calculation (Faul et al., 2007). We calculated the appropriate sample for finding an effect that is small in size $(0.2)$ at $80 \%$ power given $\alpha=0.05$. By the end of the data collection, from the 1,018 respondents that had received the survey, 403 nonprofit organizations participated (132 emails bounced back), representing 50 states and an overall response rate of $39.6 \% .^{7}$

\footnotetext{
7 This study performed several manipulation checks to exclude those who may have ignored the stimuli or failed to receive their assigned treatment. Researchers excluded eight participants from the sample based on check results. Moreover, based on the exclusion criteria used in previous literature (e.g., Mason \& Suri, 2012; Oppenheimer et al., 2009), excluded participants who took an unusually long or short time. We also excluded six participants who completed the survey too quickly (i.e., less than $120 \mathrm{~s}$ ) or too slowly (i.e., more than $15 \mathrm{~min}$ ). Before the manipulation checks, the participants took an average of 7.2 min (range $=0.20-467.85, \mathrm{SD}=23.04$ ) to complete the survey. After the checks, the average time to complete the survey was $6.1 \mathrm{~min}$ (range $=2.00-14.48, \quad \mathrm{SD}=2.45)$. This study also inspected the
} 
Fig. 1 A prospect theory framework

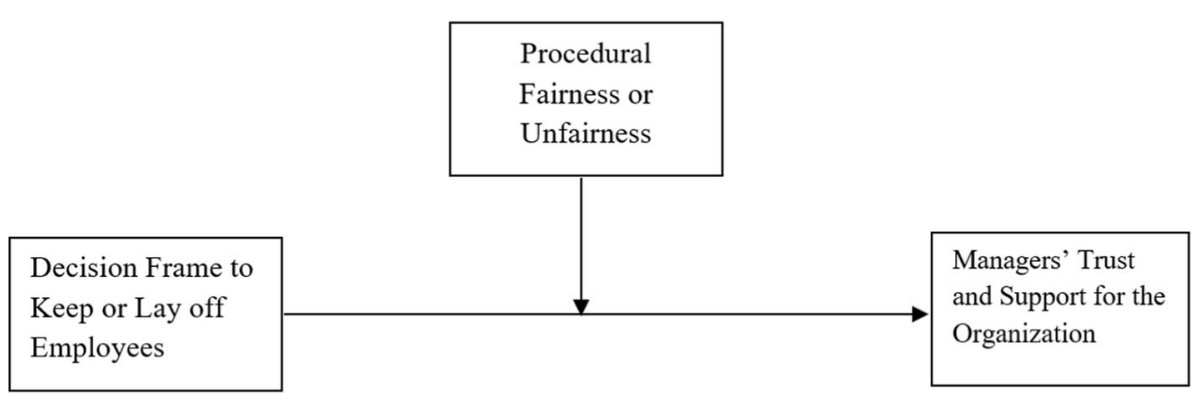

Fig. 2 Experimental design

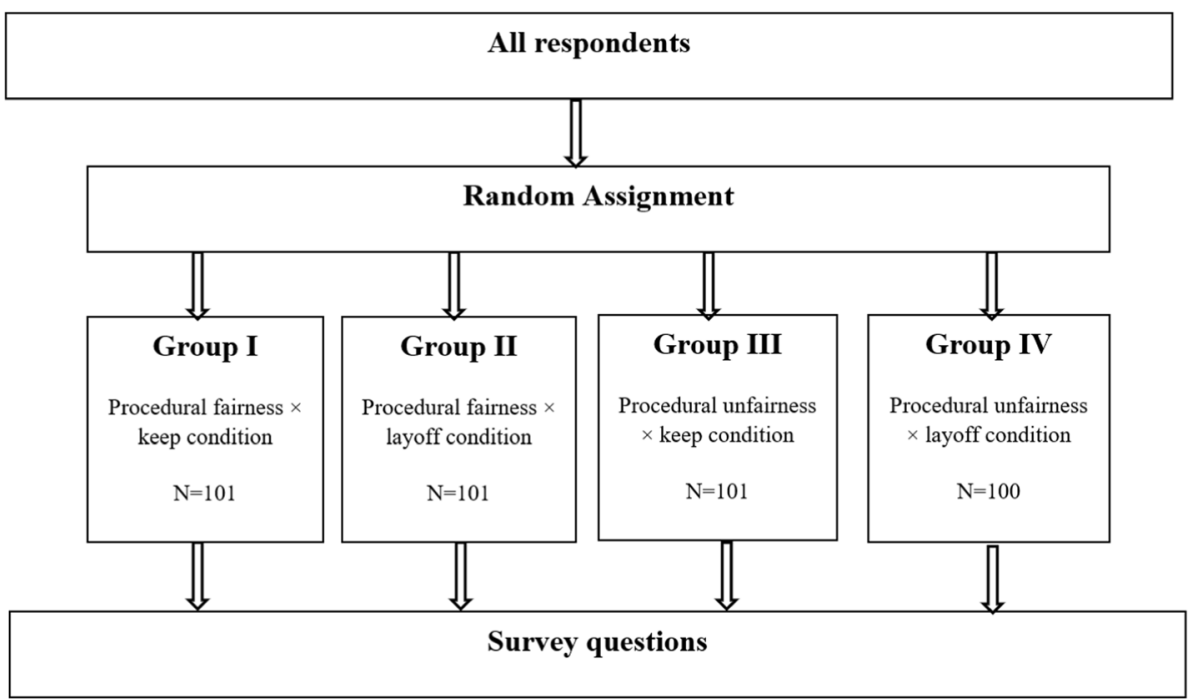

The present study sought to replicate the framing effects experiment conducted by Brockner et al. (1995), but with a different context: nonprofit organizations responding to the economic shocks from COVID-19. Thus, we can characterize our study as an empirical generalization rather than a direct or exact replication (Makel et al., 2012; Tsang \& Kwan, 1999). The survey instrument consisted of one open-ended and 16 closed-ended questions. The first section included several general questions about the services provided by nonprofit organizations, the second section contained the experimental study, and the final section included sociodemographic questions. We generated the survey items from previous studies (Battaglio \& Condrey, 2009; Brockner et al., 1995). At the end of the survey, we asked respondents, "Are there any comments you would like to add? [Optional]." We finalized the questionnaire after pretesting it with several nonprofit leaders. We

\section{Footnote 7 continued}

participants' Internet protocol (IP) addresses to ensure that none completed the survey twice (Horton et al., 2011). Further, participants responded to the item "Are you responding honestly?" using the response options "no," "maybe," and "yes" to check for their attention. We excluded four participants who failed this attention check. A total of 403 participants remained in the sample, following the manipulation checks. administered the survey online. We distributed the initial invitation to leaders in March 2020 and sent the first reminder in April 2020. We sent the second reminder in May 2020. As discussed in Dillman et al. (2014), we used multiple modes of contact in the recruitment phase of the survey to obtain high response rates and ensure that respondents prioritized answering the survey carefully. Figure 3 provides a data collection flowchart. The experimental vignette can be found in "Appendix A".

We used stratified random sampling to select the leaders of nonprofit organizations in various NTEE subgroups. Strata ensure an even distribution of leaders from different types of nonprofit organizations, and the random assignment prevents selection bias of participants on treatments (Angrist \& Pischke, 2008). Concerning organizational missions, respondents differed in percentages (see Table 1). In this study's sample, educational institutions and related activities (18.15\%), human services (12.22\%), arts, culture, and humanities $(9.26 \%)$, general and rehabilitative health $(5.93 \%)$, and housing $(5.93 \%)$ ranked high. Although this ranking is similar to the National Center for Charitable Statistics (2013), the samples used for our analysis are not a perfect representation of the entire nonprofit sector in the United States. In this sense, our study intends not to generalize our findings to the population at large but rather 
Fig. 3 Data collection flowchart
The initial invitation: March 2020

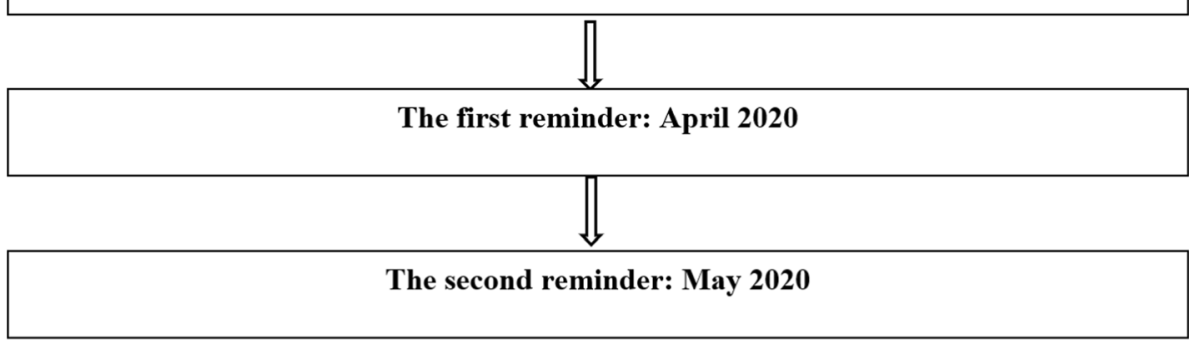

Table 1 A comparison between population and this study's sample $(\mathrm{N}=403)$

\begin{tabular}{|c|c|c|}
\hline Organizational Missions & $\begin{array}{l}\text { National Center for Charitable Statistics } \\
\text { (2013) }\end{array}$ & $\begin{array}{l}\text { National Survey of Nonprofit } \\
\text { Leaders }\end{array}$ \\
\hline A: Arts, Culture, and Humanities & $9.23 \%$ & $9.26 \%$ \\
\hline B: Educational Institutions and Related Activities & $15.74 \%$ & $18.15 \%$ \\
\hline C: Environmental Quality, Protection, and Beautification & $2.26 \%$ & $2.96 \%$ \\
\hline D: Animal Related & $2.00 \%$ & $2.59 \%$ \\
\hline E: Health—General and Rehabilitative & $8.77 \%$ & $5.93 \%$ \\
\hline F: Mental Health, Crisis Intervention & $2.85 \%$ & $3.70 \%$ \\
\hline G: Disease, Disorders, Medical Disciplines & $2.44 \%$ & $2.22 \%$ \\
\hline H: Medical Research & $0.69 \%$ & $4.73 \%$ \\
\hline I: Crime, Legal Related & $1.74 \%$ & $2.22 \%$ \\
\hline J: Employment, Job Related & $1.48 \%$ & $2.96 \%$ \\
\hline K: Food, Agriculture, and Nutrition & $1.15 \%$ & $2.22 \%$ \\
\hline L: Housing, Shelter & $7.01 \%$ & $5.93 \%$ \\
\hline M: Public Safety, Disaster Preparedness, and Relief & $1.98 \%$ & $1.11 \%$ \\
\hline N: Recreation, Sports, Leisure, Athletics & $5.91 \%$ & $4.07 \%$ \\
\hline O: Youth Development & $2.44 \%$ & $4.81 \%$ \\
\hline P: Human Services-Multipurpose and Other & $14.30 \%$ & $12.22 \%$ \\
\hline Q: International, Foreign Affairs, and National Security & $2.17 \%$ & $0.07 \%$ \\
\hline R: Civil Rights, Social Action, Advocacy & $0.66 \%$ & $2.96 \%$ \\
\hline S: Community Improvement, Capacity Building & $4.30 \%$ & $2.96 \%$ \\
\hline $\begin{array}{l}\text { T: Philanthropy, Voluntarism, and Grantmaking } \\
\text { Foundations }\end{array}$ & $4.47 \%$ & $3.33 \%$ \\
\hline U: Science and Technology Research Institutes, Services & $0.59 \%$ & $1.11 \%$ \\
\hline V: Social Service Research Institutes, Services & $0.28 \%$ & $0.04 \%$ \\
\hline W: Public. Society Benefit: Multipurpose and Other & $1.09 \%$ & $4.07 \%$ \\
\hline X: Religion Related, Spiritual Development & $6.08 \%$ & $0.11 \%$ \\
\hline Y: Mutual/Membership Benefit Organizations, Other & $0.27 \%$ & $0.27 \%$ \\
\hline Z: Unknown & $0.08 \%$ & $0.00 \%$ \\
\hline Number of Observations & 216,924 & 403 \\
\hline
\end{tabular}

to provide empirical insights into theorized processes to link procedural fairness to nonprofit managers' trust and support for their organizations. ${ }^{8}$

\footnotetext{
${ }^{8}$ To determine the difference between the sample and the population, we regressed the dependent variable-managers' trust and support for nonprofit organizations - in the presence of framing effects and
}

Using the randomizer function embedded in Qualtrics, an online survey software, we randomly assigned

Footnote 8 continued

procedural fairness (treatment), while controlling for organizational mission. The regression results confirmed no effect of the organizational mission on our finding. 
participants to one of the four treatment groups. Table 2 shows the sample's demographic characteristics. An analysis of differences between the treatment groups showed that groups were balanced at the outset: none of the differences across the groups concerning the basic organizational characteristics was statistically significant at the 0.01 level (see Table 2).

\section{Measures}

\section{Dependent Variable}

To measure the managers' trust and support for the organization, we used an index comprising the six items in Table 3. For the index design, we referred to the previous literature by Brockner et al. (1995) and Battaglio and Condrey (2009). The following text preceded the six items: "Please refer to a hypothetical scenario in which you are one of the managers at a nationwide 501(c)(3) organization called Alliance. To what extent, if at all, do you agree with the following statements as they relate to the managers' trust and support for the organization? (Select one answer in each row)" We randomized the item order. Respondents answered on a five-point scale: 1 = Strongly disagree, 2 = Somewhat disagree, $3=$ Neither agree nor disagree, 4 = Somewhat agree, and 5 = Strongly agree. We generated the index as a simple additive measure (Cronbach's $\alpha=0.88$ ).

\section{Independent Variable}

Procedural Fairness We manipulated procedural fairness along dimensions of inclusiveness or respectfulness (Tyler, 1997, 2006a, 2006b). In manipulating inclusiveness, our treatments explained whether the rank-and-file employees had opportunities to express their viewpoints to management before the layoff announcement and whether those laid off had opportunities to appeal their layoff. In manipulating respectfulness, our treatment explained whether local management clarified the layoff reasons to the laid-off employees and whether local management expressed regret about the layoffs (see "Appendix A").

Framing Effects One section of the survey asked participants a series of questions about the organization's criteria for identifying employees to be laid off. The following text preceded the six items: "Management could have used the following factors to decide which employees would keep their jobs/be laid off and which employees would not during the layoffs. To what extent do you believe that each of the following factors actually would have been used to decide which employees would keep their jobs/be laid off?" As with previous items, we randomized the item order, and the respondents answered on a five-point scale: $1=$ Not at all, $2=$ A little, $3=A$ moderate amount, $4=$ A lot, and $5=$ A great deal .

We bolstered the framing effects manipulation with the definition accompanying each of the six criteria rated by participants. For example, in the keep condition, information about "job function" included that "those who kept their jobs during the job layoffs might have been in jobs identified as essential." In the layoff condition, contrarily, we pointed out that "the laid-off during the job layoffs might have been in jobs identified as no longer essential." In the survey, the framing effects manipulation preceded most procedural fairness items and all dependent variables.

\section{Findings}

We discuss the descriptive results before moving on to the experimental findings in response to hypothetical job layoffs. Table 4 contains some descriptive statistics for the 403 U.S. nonprofit organizations under examination. ${ }^{9}$ The sample comprises young and old organizations, with an age range from 4.55 to 143 years. As the data demonstrate, there is high variability in some variables - particularly for donations, fundraising, program expenses, size, and revenue. In addition, the variable of size has four organizations with negative values for their assets.

This study asked nonprofit executive directors about their prospects for job layoffs in the U.S. nonprofit sector over the next five years. For job layoff expectations, we measured the level of layoffs on a three-point scale, where 1 indicates no job layoffs, 2 is modest job layoffs, and 3 is substantial job layoffs. When asked, "How would you expect the job layoffs in the U.S. nonprofit sector's response to the economic shock of COVID-19 over the next five years," 33 respondents (18.33\%) expected "substantial job layoffs," while 66 respondents (36.67\%) expected "modest job layoffs." These results show that the respondent group virtually expected job layoffs to continue five years after the study. Figure 4 shows respondents' expectations of job layoffs in the next five years. ${ }^{10}$

\footnotetext{
$\overline{9}$ This study used Form 990 data drawn from the 2020 filings available at the time of the study.

${ }^{10}$ According to this study, only 55\% (36.67\% plus $18.33 \%$ ) of respondents predicted modest or substantial layoffs in the next five years, whereas $45 \%$ of respondents predicted no layoffs in the next five years. We can interpret these descriptive statistics in the following two ways. First, there are the consequences of deep budget cuts from coronavirus's painful side effects including altered work hours, reductions in pay, furloughs, leave options, unfilled vacant positions, consolidating departments, and reordering of spending priorities in addition to layoffs (Kuenzi et al., 2021). It is possible that expectations for these other cutback options may be higher than layoffs. Second, the time frame of this study is March 2020 through
} 
Table 2 Respondents' characteristics and organizational context across groups

\begin{tabular}{|c|c|c|c|c|c|c|c|c|}
\hline Category & Subgroup & $\begin{array}{l}\text { Procedural fairness } \\
\times \text { keep condition }(\%) \\
(\mathrm{n}=101)\end{array}$ & $\begin{array}{l}\text { Procedural fairness } \\
\times \text { layoff condition } \\
(\mathrm{n}=101)\end{array}$ & $\begin{array}{l}\text { Procedural } \\
\text { unfairness } \\
\times \text { keep condition } \\
(\mathrm{n}=101)\end{array}$ & $\begin{array}{l}\text { Procedural } \\
\text { unfairness } \\
\times \text { layoff } \\
\text { condition } \\
(\mathrm{n}=100)\end{array}$ & $\chi^{2}$ & df & $p$ value \\
\hline Current & $\begin{array}{r}\text { Executive } \\
\text { Director }\end{array}$ & 85.71 & 57.23 & 59.38 & 48.28 & 11.883 & 6 & 0.688 \\
\hline \multirow[t]{6}{*}{ Position } & $\begin{array}{l}\text { Chief Executive } \\
\text { Director }\end{array}$ & 0.00 & 14.29 & 15.63 & 22.41 & & & \\
\hline & Deputy Director & 0.00 & 0.00 & 9.00 & 1.72 & & & \\
\hline & $\begin{array}{l}\text { Program } \\
\text { Coordinator }\end{array}$ & 0.00 & 14.29 & 6.25 & 1.72 & & & \\
\hline & Manager & 0.00 & 0.00 & 6.25 & 10.34 & & & \\
\hline & $\begin{array}{l}\text { Publicist/ } \\
\text { Marketing }\end{array}$ & 0.00 & 0.00 & 0.00 & 0.00 & & & \\
\hline & Other & 14.29 & 14.29 & 12.49 & 15.53 & & & \\
\hline \multirow[t]{6}{*}{ Race } & $\begin{array}{l}\text { Black/African } \\
\text { American }\end{array}$ & 0.00 & 33.33 & 6.25 & 0.00 & 17.933 & 5 & 0.118 \\
\hline & White & 85.71 & 66.67 & 68.75 & 87.72 & & & \\
\hline & $\begin{array}{l}\text { Asian/Pacific } \\
\text { Islander }\end{array}$ & 14.29 & 0.00 & 12.50 & 3.51 & & & \\
\hline & Native American & 0.00 & 0.00 & 0.00 & 0.00 & & & \\
\hline & Other & 0.00 & 0.00 & 6.25 & 5.26 & & & \\
\hline & $\begin{array}{l}\text { Prefer not to } \\
\text { answer }\end{array}$ & 0.00 & 0.00 & 6.25 & 3.51 & & & \\
\hline \multirow[t]{2}{*}{ Gender } & Female & 57.14 & 66.67 & 65.63 & 59.65 & 0.437 & 1 & 0.933 \\
\hline & Male & 42.86 & 33.33 & 34.37 & 40.35 & & & \\
\hline \multirow[t]{8}{*}{ Population } & 10,000 to 24,999 & 14.29 & 0.00 & 9.38 & 0.00 & 20.175 & 7 & 0.510 \\
\hline & 25,000 to 49,999 & 14.29 & 0.00 & 3.13 & 5.36 & & & \\
\hline & 50,000 to 99,999 & 0.00 & 0.00 & 6.25 & 14.29 & & & \\
\hline & $\begin{array}{c}100,000 \text { to } \\
249,999\end{array}$ & 14.29 & 16.66 & 21.82 & 16.07 & & & \\
\hline & $\begin{array}{c}250,000 \text { to } \\
499,999\end{array}$ & 14.29 & 0.00 & 15.63 & 8.93 & & & \\
\hline & 500,000 or more & 42.84 & 66.68 & 40.66 & 46.43 & & & \\
\hline & Not sure & 0.00 & 16.66 & 3.13 & 7.14 & & & \\
\hline & Refuse & 0.00 & 0.00 & 0.00 & 1.78 & & & \\
\hline \multirow[t]{4}{*}{ Region } & Northeast & 16.66 & 16.66 & 37.50 & 23.21 & 7.027 & 3 & 0.634 \\
\hline & Midwest & 16.66 & 0.00 & 3.13 & 12.50 & & & \\
\hline & South & 16.66 & 33.32 & 28.13 & 30.36 & & & \\
\hline & West & 50.02 & 50.02 & 31.24 & 33.93 & & & \\
\hline
\end{tabular}

Then, this study explains the experimental findings on the framing effects on the managers' trust and support for the organization, contingent upon procedural fairness. Table 5 presents the result of OLS regression on the

\section{Footnote 10 continued}

May 2020, which is very early in the pandemic. The result might have been different if we conducted this study in the fall of 2021, when researchers expect declining revenue and unexpected expenditures to persist over the next two to three years because of the pandemic. moderating role of procedural fairness on the framing effects on managers' reactions to job layoffs. For Table 5, the statistically significant regression coefficient of the interaction between procedural unfairness and layoff/keep conditions means that procedural unfairness has a moderating effect. On the other hand, the regression coefficient of the interaction between procedural fairness and layoff/keep conditions is statistically insignificant, indicating that procedural fairness has no moderating effect. Specifically, 
Table 3 Survey questions regarding the managers' trust in and support for the organization

\begin{tabular}{lrr}
\hline & $\begin{array}{c}\text { Mean } \\
\text { Range }\end{array}$ & $\begin{array}{l}\text { Standard } \\
\text { deviation }\end{array}$ \\
\hline The managers' trust in and support for the organization (index): & 2.26 & 0.99 \\
"The managers trust local _ management" & 3.20 & 1.32 \\
"The managers are proud to tell others that they are a part of _The & 3.14 & 1.22 \\
"The managers' co-workers might have been quite mistrustful of top management since the beginning of & 2.16 & 1.07 \\
the layoff"* & 2.82 & $1-5$ \\
"Managers treat survivors fairly and consistently with respect to HR" & 3.27 & 1.33 \\
"The managers trust management with respect to HR decisions" & 3.29 & 1.32 \\
\hline
\end{tabular}

Note $*$ Item was reverse coded to create the managers' trust in and support for the organization index

Table 4 Descriptive statistics

\begin{tabular}{llll}
\hline Variable & Mean (SD) & Min & Max \\
\hline Donations & $1,853,722(32,914,313)$ & 0 & $8,550,169,316$ \\
Fundraising & $20,718(226,200)$ & 0 & $41,092,401$ \\
Program & $7,607,045(166,154,527)$ & 0 & $62,244,776,774$ \\
$\quad$ Expenses & & & \\
Age & $34.49(97.98)$ & 4.99 & 143 \\
Size & $21,520,490(391,035,676)$ & $-3,165,084$ & $90,501,091,616$ \\
Revenue & $10,153,694(179,460,831)$ & 111 & $62,519,341,516$ \\
\hline
\end{tabular}

Note Values are expressed in US dollars

How would you expect the job layoffs in the U.S. nonprofit sector response to the economic shock of COVID-19 over the next five years?

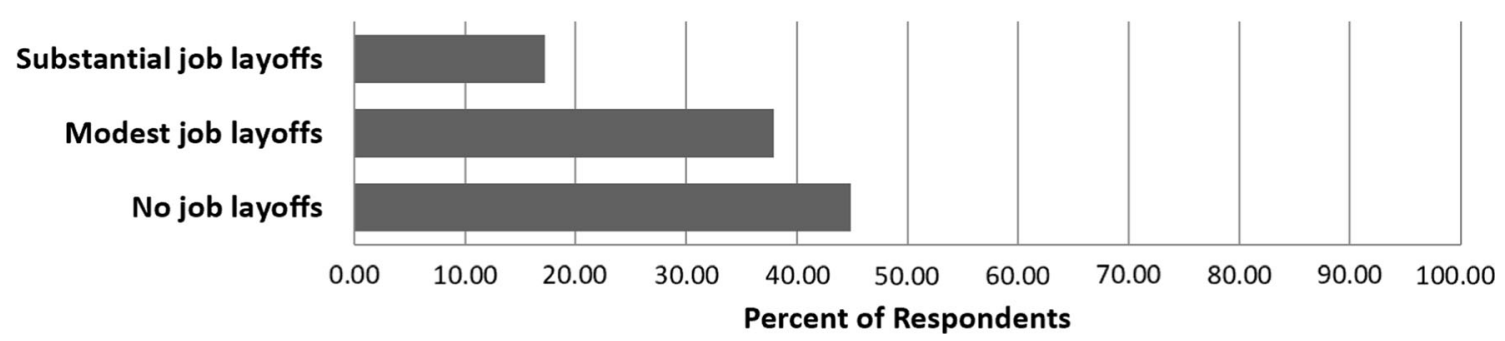

Fig. 4 Respondents' expectations of job layoffs in the next five years

managers perceived the layoff condition as negative and the keep condition as positive only when procedurally unfair. For procedural fairness, however, we observed no difference in the managers' response to the layoff and keep conditions for procedural fairness. This result means that framing effects on the managers' trust and support for the organization vary depending on whether the procedure is fair or unfair.

Figure 5 illustrates the magnitude of these procedural fairness effects by plotting marginal framing effects on the managers' reactions to job layoffs, contingent upon procedural fairness. The proper test for our hypothesis is to examine whether the differences between procedural fairness $\times$ keep and procedural fairness $\times$ layoff, and between procedural unfairness $\times$ keep and procedural unfairness $\times$ layoff, are statistically significant. In Fig. 5, when the decision-making procedure was unfair, the difference between the keep and layoff conditions is statistically significant because $95 \%$ confidence intervals of those conditions did not overlap at procedural unfairness. However, when the decision-making procedure was fair, the difference between the keep and layoff conditions was not statistically significant because $95 \%$ confidence intervals overlapped at procedural fairness. When the procedurally fair and unfair conditions are combined, the difference between the keep and the layoff conditions is statistically 
Table 5 OLS regression results on the moderating role of procedural fairness on the managers' reactions to job layoffs in response to the economic shock of COVID-19

\begin{tabular}{|c|c|c|c|c|}
\hline \multirow[t]{2}{*}{ DV $=$ Managers' Trust and } & \multicolumn{4}{|c|}{ Support for the organization } \\
\hline & \multicolumn{2}{|l|}{ Model 1} & \multicolumn{2}{|l|}{ Model 2} \\
\hline $\begin{array}{l}\text { Procedural Fairness } \\
(\text { Fair }=1)\end{array}$ & $\begin{array}{l}0.844 \\
(0.189)\end{array}$ & $* * *$ & $\begin{array}{l}0.408 \\
(0.098)\end{array}$ & $* *$ \\
\hline Procedural Fairness $\times$ Keep & Ondition & & $\begin{array}{l}0.556 \\
(0.311)\end{array}$ & \\
\hline $\begin{array}{l}\text { Keep Condition } \\
(\text { Keep }=1)\end{array}$ & $\begin{array}{l}0.101 \\
(0.283)\end{array}$ & $* * *$ & $\begin{array}{l}0.306 \\
(0.409)\end{array}$ & ** \\
\hline Procedural Fairness $\times$ Layof & Condition & & $\begin{array}{l}-0.233 \\
(0.423)\end{array}$ & \\
\hline $\begin{array}{l}\text { Procedural Unfairness } \\
(\text { Unfair }=1)\end{array}$ & $\begin{array}{l}-0.500 \\
(0.531)\end{array}$ & $* * *$ & $\begin{array}{l}-0.395 \\
(0.569)\end{array}$ & $* *$ \\
\hline Procedural Unfairness $\times \mathrm{Ke}$ & Condition & & $\begin{array}{l}0.267 \\
(0.423)\end{array}$ & $* *$ \\
\hline $\begin{array}{l}\text { Layoff Condition } \\
(\text { Layoff }=1)\end{array}$ & $\begin{array}{l}-0.408 \\
(0.569)\end{array}$ & $* * *$ & $\begin{array}{l}-0.339 \\
(0.292)\end{array}$ & $* * *$ \\
\hline Procedural Unfairness $\times$ Las & ff Condition & & $\begin{array}{l}-0.895 \\
(0.203)\end{array}$ & $* * *$ \\
\hline Constant & $\begin{array}{l}2.700 \\
(0.281)\end{array}$ & $* * *$ & $\begin{array}{l}2.028 \\
(0.376)\end{array}$ & $* *$ \\
\hline $\mathrm{N}$ & 403 & & 403 & \\
\hline Adjusted R2 & 0.152 & & 0.147 & \\
\hline
\end{tabular}

Note Standard errors in parentheses; DV, dependent variable. * $\mathrm{p}<0.10 ; * * \mathrm{p}<0.05 ; * * \mathrm{p}<0.01$ (two-tailed tests) significant. This outcome suggests that procedural unfairness significantly impacts the managers' trust and support for the organizations compared to procedural fairness. In other words, when we combined procedurally fair and unfair cases, there was also a difference in the managers' responses. At the same time, there was a difference in managers' reactions to the layoff and keep conditions only when the decision-making procedure was procedurally unfair and not in the case of procedural fairness.

Regarding the size of the effects, the marginal effect of the decision frame on trust and support for the organization is 2.83 for the positive frame (keep) and 1.94 for the negative frame (layoff) condition when the decision-making procedure was procedurally unfair. When it is procedurally fair, the marginal effect of the decision frame on trust and support for the organization is 2.53 for the positive frame (keep) and 2.03 for the negative frame (layoff) condition. Finally, when combining procedural fairness and unfairness, the marginal effect of the decision frame on trust and support for the organization is 2.8 for the positive frame (keep) and 1.95 for the negative frame (layoff) condition. These values correspond to increases by 0.89 when procedurally unfair, 0.5 when procedurally fair, and 0.85 in combined procedural fairness and unfairness. The $p$ values are statistically significant only in the procedurally unfair and combined (procedural fairness + unfairness) conditions with the magnitude of the effect appearing large.
Fig. 5 Marginal effects of decision frame on the managers' trust in and support for the organization, contingent upon procedural fairness $(95 \%$ confidence intervals)
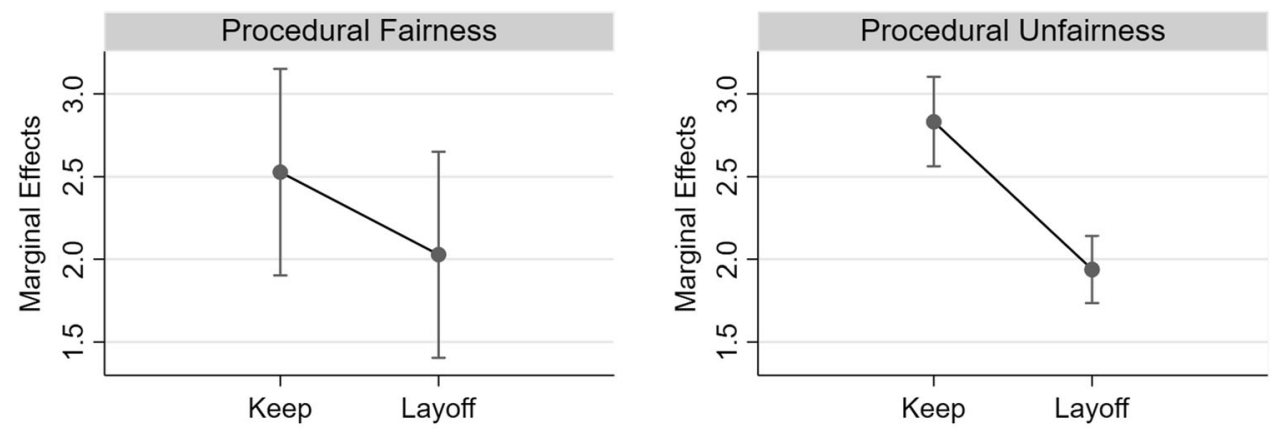

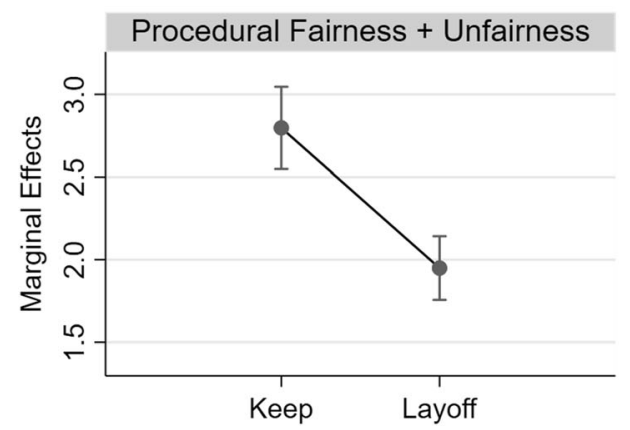




\section{Discussion and Conclusion}

This replication study complements previous research by examining the effects of decision frames on managers' reactions to job layoffs in the context of nonprofit organizations anticipating layoffs during the COVID-19 pandemic. The results align with the initial findings of Brockner et al. (1995) in that procedural fairness plays a vital role in nonprofit organizations: managers who perceive mistreatment of laid-off workers during extreme events will be less motivated to perform jobs well. Moreover, framing effects play a complementary role: framing influences individuals' perceptions of outcome favorability. In other words, we find that nonprofit managers are prone to be influenced by superficial changes in the valence of discharge information when asked to read and interpret said information. More precisely, results from our experiment confirm equivalence framing effects on managers' trust and support for their organizations.

Our findings suggest that positively framing the discharge information convinced those who worked under procedurally unfair conditions. Interestingly, a similar pattern is not present for the relationship when it is procedurally fair. In other words, when it is procedurally fair, there is no difference in respondents' reactions to the keep and layoff conditions. This result suggests an asymmetric effect of framing on the managers' reactions to job layoffs.

Compared with May 2020, when the data for this study was collected, some employers may be more reluctant to lay off staff at this moment due to the American Rescue Plan Act. Most nonprofit managers are having to adjust because in most cases their staffs are underpaid via grant funding. Even if they were at work, they would not earn as much as they could through Economic Impact Payments (EIPs) and unemployment benefits. ${ }^{11}$ This is because nonprofit employers can only offer low salaries because they have insufficient funding due to reductions in grant funding.

If the nonprofit organizations experienced a decline in trust from their staff since May 2020, when we completed our data collection, until now, the decreased confidence might reflect management's response to protecting the

\footnotetext{
11 The American Rescue Plan Act authorized the IRS to provide up to 1,400 U.S. dollars as a third round of EIPs (also known as stimulus payments) for people whose jobs have been affected by the coronavirus pandemic. In addition, most staff would rather be unemployed because they can get approximately 480 U.S. dollars per week for staying at home. The Act temporarily authorized: (1) an extension of people already receiving unemployment benefits (about 180 U.S. dollars per week), (2) automatic, additional payments of 300 U.S. dollars per week to everyone qualified for unemployment benefits, and (3) extension of the Pandemic Unemployment Assistance (PUA) program for self-employed or gig workers (COVID-19 Unemployment Benefits, 2021).
}

organization. Management acts to sustain the organization when faced with reduced funding. In other words, the managers would feel that the top management will not consider their needs first. It is doubtful that the managers would feel otherwise. During funding reductions, managers' trust in their superiors would wane because upper management must consider the overall operation and not just one particular program. This action is despite that each program is equally vital to serving the public. During such times as the coronavirus pandemic, upper management finds a way to plan for serving the public with reduced funding, even if it means providing services to fewer people. For instance, if an organization receives a five percent cut in nonprofit grants from a foundation, corporation, or government agency, it can still serve the same clients but with five percent fewer services.

We found that only when job layoffs were procedurally unfair did managers have less trust in their organization due to job layoffs in response to COVID-19. For example, this would be true if upper management reduced staff for unwarranted reasons such as political affiliation. However, upper management typically reviews its staffing situation and makes recommendations about staffing or programming reductions based upon many years of experience.

Before discussing the study's implications, we review the limitations that pave the way for future research. First, nonprofit executives are the subjects of this study. Future studies can further deal with the effects of job layoffs by selecting nonprofit workers at more diverse levels. Notwithstanding these limitations, our research findings support our moderation model. For example, if the board of directors laid off its street-level employees, it may negatively influence the managers' trust and support for the organization. In other words, we expect no significant difference if respondents are leaders or frontline workers. Instead, since nonprofit leaders have experienced job layoffs during past economic crises such as the financial crises between June 2007 and December 2009, we expect the respondents to provide an expert opinion when encountering similar situations due to COVID-19. However, in addition to nonprofit leaders' perceptions, future research needs to study how street-level employees perceive job layoffs to determine the robustness of these findings.

A second limitation is the abstract nature of our experiment. A personal stake in the job layoff decision likely matters, but the survey does not directly relate to the respondents' interests because they answered based on a hypothetical scenario. Despite this valid criticism, it is important to think creatively about what will happen in the post-pandemic era because it is unclear when the pandemic will end. Particularly in the case of unexpected public health crises such as COVID-19, it is vital to conduct an experimental design to account for a fourth wave or similar 
economic effects driven by the Delta variant. As such, experiments can provide a window into the impact of procedural fairness on trust that might otherwise be impossible to obtain using alternative research designs.

Lastly, the study offers a snapshot of a single period in time, namely March through May 2020 - the early stage of the COVID-19 pandemic in the U.S. Therefore, unlike a longitudinal study, it may not provide specific information about changes over time. Moreover, at the time of this writing, the path of the post-COVID pandemic and its economic consequences remain uncertain. One key source of the uncertainty stems from the intermittent containment remaining in force for longer than expected. For example, the vaccination effort progresses slowly in some advanced economies, and new outbreaks occur, such as the Delta variant in developing economies (Cave, 2021). Nevertheless, we need to understand how the unprecedented crisis of the COVID-19 pandemic impacts nonprofit managers and their commitment to working in the sector. This is because nonprofit organizations face increased demands for services alongside decreased revenues and must make tough decisions to weather these fiscal storms.

Notwithstanding these limitations, our findings offer several vital contributions. First, and perhaps most importantly, procedural fairness, more than the outcome favorability itself, appears to form the basis for nonprofit managers' trust and support for their organizations. As demonstrated, when procedural fairness is low, nonprofit managers respond very favorably to keep conditions and very negatively to layoff conditions. Their responses are perhaps because nonprofit workers are the lifeblood enabling nonprofit organizations to deliver services that ultimately generate shareholder benefits. For instance, Knapp et al. (2019) argued that nonprofit managers should receive training to apply organizational policies consistently and equitably. In addition, the organization should clearly explain the underlying rationale behind its decisions (i.e., layoffs). It is also crucial that nonprofit managers receive training on treating employees with respect and politeness when resorting to layoffs. For all nonprofit organizations, planning thoughtful workforce change amidst embedded layoffs in nonprofit organizations as a short-term solution for lowering costs can be a better way to address the vicissitudes of the transition in the economic landscape due to the adverse economic prospects of COVID-19.

The study's second contribution is a practical implication for nonprofit organizations facing layoffs due to the economic shocks of COVID-19. Whenever nonprofit organizations have a layoff situation, this creates fear in managers. All managers want security in their employment. When organizations initiate a layoff action, the more information they can provide their managers about any layoff action, the better. The managers want to know why, who is affected, and whether the layoff is temporary or permanent. They also want to know the process of choosing which positions to include in the layoffs and if they have any rights to voluntarily move to lower-level positions instead of being included in the layoff action. Answering these questions goes a long way in relieving tensions between the board and managers. Managers have a challenging time fighting a layoff action for "reason of economy," meaning that, for instance, there is insufficient funding for all proposed positions. While the layoff action is the most reasonable conclusion by top management, hurt feelings are inevitable because the managers' livelihoods are at stake. Being forthright about the organizations' situation and its intent to maintain as many managers as possible will help maintain organizational trust and support.

Lastly, nonprofits in the post-COVID-19 environment require nonprofit managers to ensure decision-making accuracy, consistency, and comprehensiveness. In addition, designing transparent decision-making processes and institutionalizing regulations to ensure accountability and responsibility for their decisions is challenging in nonprofit management (Delronge et al., 2019). Accordingly, the transition to this ever-changing environment and stakeholder needs demands a leadership commitment to creating a culture of trust based on all internal and external collaborators' commitments to integrity and transparency. A commitment to integrity would positively affect the social capital dimension of employee and institutional trust among all the collaborators. And the level of trust could be one of the most important driving factors for the speedy development of organizational routines of nonprofit organizations' ability to thrive in the current environment and future through effective information-sharing, inclusive feedback, and co-creation of values.

This article provides early evidence that the implications of procedural fairness - mainly framing effects - are not as straightforward as is often assumed. Instead, the relationship between framing effects and trust is asymmetric: framing effects matter only in a procedurally unfair condition, but framing effects do not matter when the decisionmaking procedure is fair. We wrote this article when the U.S. daily infection rates were still high. Thus, we need further analysis to assess the negative impacts of COVID19 on the nonprofit sector as a whole. Nevertheless, the potential for using prospect theory in developing nonprofit organizations' resilience strategies to lessen the shocks associated with such crises is a good start. 


\section{Appendix}

\section{Appendix A: Experimental Vignettes}

(1) Layoff condition.

Management could have used the following factors to decide which employees would be laid off and which would not during the layoffs. To what extent do you believe that each of the following factors actually would have been used to decide which employees would be laid off?

Performance merit: Those
who are laid off during the
job layoffs might not have
received merits because they
perform their jobs
ineffectively.
Seniority: Those who
are laid off during the job
layoffs might hare been in an
underprivileged position
because of shorter service or
lower rank.
Politics: Those persons who
are laid off during the job
layoffs might have
been unsuccessful in the
conflict among individuals or
parties who have or hope to
achieve power.
Skills: Those who are laid
off during the job layoffs
might not have had the
ability to work well.
Randomness: Those
persons who are laid off
during the job layoffs might
have been chosen randomly.
Job Function: Those who
are laid off during the job
layoffs might have been in
jobs that were identified as
no longer essential.

(2) Keep condition. 
Management could have used the following factors to decide which employees would keep their jobs and which would not during the job layoffs. To what extent do you believe that each of the following factors actually would have been used to decide which employees would keep their jobs?

Performance merit: those
who kept their jobs during
the job layoffs might have
received merits because they
perform their jobs
effectively.
Seniority: Those who kept
their jobs during the job
layoffs might have been in a
privileged position because
of longer service or higher
rank.
Politics: Those who kept
their jobs during the job
layoffs might have
been successful in the
conflict among individuals or
parties who have or hope to
achieve power.
Skills: Those who kept their
jobs during the job layoffs
might have had the ability to
work well.
Randomness: Those who
kept their jobs during the job
layoffs might have been
chosen randomly.
Job Function: Those who
kept their jobs during the job
layoffs might have been in
jobs that were identified as
essential.

(3) Procedural unfairness.

Please refer to the following hypothetical scenario: Compared to other nonprofit organizations that also are having layoffs, Alliance has generally been unfair in the way that it has handled their layoff process. Before the layoff was announced, the rank and file had very few opportunities to express their viewpoints to management. Consistent standards were not followed in deciding which employees to layoff. Management had very inaccurate information on which to base their decision that the layoff was necessary. Those laid off had very few opportunities to appeal their layoff. Local management explained the reasons for the layoff to the laid off employees very ambiguously, and expressed very little regret that individuals were being laid off.

\section{(4) Procedural fairness.}


Please refer to the following hypothetical scenario: Compared to other nonprofit organizations that also are having layoffs, Alliance has generally been fair in the way it has handled the layoff process. Before the layoff was announced, the rank and file had many opportunities to express their viewpoints to management. Consistent standards were followed strictly in deciding which employees to layoff. Management had very accurate information on which to base their decision that the layoff was necessary. Those laid off had many opportunities to appeal their layoff. Local management explained the reasons for the layoff to the laid off employees very clearly, and expressed a great deal of regret that individuals were being laid off.

(5) The managers' trust in and support for their organizations.

Please refer to a hypothetical scenario in which you are one of the managers at a nationwide 501(c)(3) organization called Alliance. To what extent, if at all, do you agree with the following statements as they relate to the managers' trust and support for the organization? (Select one answer in each row.)

\begin{tabular}{|c|c|c|c|c|c|}
\hline & Strongly agree & $\begin{array}{l}\text { Somewhat } \\
\text { agree }\end{array}$ & $\begin{array}{c}\text { Neither agree } \\
\text { nor disagree }\end{array}$ & $\begin{array}{l}\text { Somewhat } \\
\text { disagree }\end{array}$ & $\begin{array}{l}\text { Strongly } \\
\text { disagree }\end{array}$ \\
\hline $\begin{array}{l}\text { The managers trust local } \\
\text { management. }\end{array}$ & 0 & 0 & 0 & 0 & 0 \\
\hline $\begin{array}{l}\text { The managers are proud to } \\
\text { tell others they are a part of } \\
\text { the }\end{array}$ & 0 & 0 & 0 & 0 & 0 \\
\hline $\begin{array}{l}\text { The managers' co-workers } \\
\text { might have been quite } \\
\text { mistrustful of top } \\
\text { management since the layoffs } \\
\text { began. }\end{array}$ & 0 & 0 & 0 & 0 & 0 \\
\hline $\begin{array}{l}\text { Managers treat survivors } \\
\text { fairly and consistently with } \\
\text { respect to } \mathrm{HR} \text {. }\end{array}$ & 0 & 0 & 0 & 0 & 0 \\
\hline $\begin{array}{l}\text { The managers trust } \\
\text { management with respect to } \\
\text { HR decisions. }\end{array}$ & 0 & 0 & 0 & 0 & 0 \\
\hline $\begin{array}{l}\text { The managers feel that they } \\
\text { can trust the organization to } \\
\text { treat them fairly. }\end{array}$ & 0 & 0 & 0 & 0 & 0 \\
\hline
\end{tabular}

\section{References}

Angrist, J., \& Pischke, J. (2008). Mostly harmless econometrics: An empiricist's companion. Princeton University Press.

Battaglio, R. P., \& Condrey, S. E. (2009). Reforming public management: Analyzing the impact of public service reform on organizational and managerial trust. Journal of Public Administration Research and Theory, 19(4), 689-707.

Brockner, J., Wiesenfeld, B. M., \& Martin, C. L. (1995). Decision frame, procedural justice, and survivors' reactions to job layoffs. Organizational Behavior and Human Decision Processes, 63(1), 59-68.
Cave, D. (2021, July 2). Why the Delta variant could end Australia's pursuit of 'Covid zero.' The New York Times. https://www. nytimes.com/2021/07/02/world/australia/delta-covid-zero.html

Chang, C. T. (2008). To donate or not to donate? Product characteristics and framing effects of cause-related marketing on consumer purchase behavior. Psychology \&amp; Marketing, 25(12), 1089-1110.

Chang, C. T., \& Lee, Y. K. (2009). Framing charity advertising: Influences of message framing, image valence, and temporal framing on a charitable appeal. Journal of Applied Social Psychology, 39(12), 2910-2935.

Courtemanche, C., Garuccio, J., Le, A., Pinkston, J., \& Yelowitz, A. (2020). Strong social distancing measures in the United States reduced the COVID-19 growth rate. Health Affairs, 39(7), 1237-1246. 
Delronge, C., Ducato, R., Kleczewski, A., Marique, E., Strowel, A., \& Wattecamps, C. (2019). Policy framework for digital platforms: Moving from openness to inclusion. Protection of users in the platform economy: A European perspective. Belgium: International Development Research Centre, UCLouvain.

Dillman, D. A., Smyth, J. D., \& Christian, L. M. (2014). Internet, phone, mail, and mixed-mode surveys: The tailored design method. Wiley.

Eagle Hill Consulting. (2021). 2021 Nonprofit outlook: Employeedriven change. https://www.eaglehillconsulting.com/insights/ 2021-nonprofit-employee-change-management/.

Faul, F., Erdfelder, E., Lang, A.-G., \& Buchner, A. (2007). G* Power 3: A flexible statistical power analysis program for the social, behavioral, and biomedical sciences. Behavior Research Methods, 39(2), 175-191.

Fuenzalida, J., Van Ryzin, G. G., \& Olsen, A. L. (2020). Are managers susceptible to framing effects? An experimental study of professional judgment of performance metrics. International Public Management Journal., 24(3), 314-329. https://doi.org/10. 1080/10967494.2020.1752338

Greiling, D. (2007). Trust and performance management in non-profit organizations. The Innovation Journal: Public Sector Innovation Journal, 12(3), 1-23.

Horton, J. J., Rand, D. G., \& Zeckhauser, R. J. (2011). The online laboratory: Conducting experiments in a real labor market. Experimental Economics, 14(3), 399-425.

Kim, M., \& Mason, D. P. (2020). Are you ready: Financial management, operating reserves, and the immediate impact of COVID-19 on nonprofits. Nonprofit and Voluntary Sector Quarterly, 49(6), 1191-1209.

Knapp, J. R., Sprinkle, T. A., Urick, M. J., \& Delaney-Klinger, K. A. (2019). The belonging model of trust. Nonprofit Management \&amp; Leadership, 30(1), 133-153.

Kuenzi, K., Stewark, A. J., \& Walk, M. (2021). COVID-19 as a nonprofit workplace crisis: Seeking insights from the nonprofit workers' perspective. Nonprofit Management and Leadership, 31(4), 821-832.

Lanfranchi, J., Narcy, M., \& Larguem, M. (2010). Shedding new light on intrinsic motivation to work: Evidence from a discrete choice experiment. Kyklos, 63(1), 75-93.

Makel, M. C., Plucker, J. A., \& Hegarty, B. (2012). Replications in psychology research: How often do they really occur? Perspectives on Psychological Science, 7(6), 537-542.

Mani, S., \& Mishra, M. (2020). Non-monetary levers to enhance employee engagement in organizations - "GREAT" model of motivation during the COVID-19 crisis. Strategic HR Review, 19(4), 171-175.

Mason, W., \& Suri, S. (2012). Conducting behavioral research on Amazon's Mechanical Turk. Behavior Research Methods, 44(1), $1-23$.

Olsen, A. L. (2015). Citizen (dis) satisfaction: An experimental equivalence framing study. Public Administration Review, 75(3), 469-478.

Oppenheimer, D. M., Meyvis, T., \& Davidenko, N. (2009). Instructional manipulation checks: Detecting satisficing to increase statistical power. Journal of Experimental Social Psychology, 45(4), 867-872.

Passetti, E., Battaglia, M., Bianchi, L., \& Annesi, N. (2021). Coping with the COVID-19 pandemic: The technical, moral, and facilitating role of management control. Accounting, Auditing, \&amp; Accountability Journal, 34(6), 1430-1444.

Piening, E. P. (2011). Insights into the process dynamics of innovation implementation. Public Management Review, 13(1), $127-157$.

Qu, H., \& Daniel, J. L. (2021). Is "overhead" a tainted word? A survey experiment exploring framing effects of nonprofit overhead on donor decision. Nonprofit and Voluntary Sector Quarterly, 50(2), 397-419.

Salamon, L. M., \& Newhouse, C. L. (2020). The 2020 nonprofit employment report. Nonprofit Economic Data Bulletin no. 48. Baltimore, MD: Johns Hopkins Center for Civil Society Studies.

Terblanche, N. H. D. (2021). Managers' responses to the initial stages of the COVID-19 pandemic: An executive coaching perspective. Personnel Review. https://doi.org/10.1108/PR-07-2020-0540

The NonProfit Times. (2020). Nonprofit COVID response job layoff spiking. The NonProfit Times. https://www.thenonprofittimes. $\mathrm{com} / \mathrm{hr} /$ nonprofit-covid-response-job-layoffs-spiking/

Tsang, E. W., \& Kwan, K.-M. (1999). Replication and theory development in organizational science: A critical realist perspective. Academy of Management Review, 24(4), 759-780.

Tyler, T. R. (2006a). What do they expect? New findings confirm the precepts of procedural fairness. California Court Review, 22-24.

Tyler, T. R. (1991). Using procedures to justify outcomes: Testing the viability of a procedural justice strategy for managing conflict and allocating resources in work organizations. Basic and Applied Social Psychology, 12(3), 259-279.

Tyler, T. R. (1997). The psychology of legitimacy: A relational perspective on voluntary deference to authorities. Personality and Social Psychology Review, 1(4), 323-345.

Tyler, T. R. (2006b). Why people obey the law. Princeton University Press.

Vroom, V. H. (1964). Work and motivation. John Wiley.

Yin, R. K. (2003). Case study research: Design and methods. Sage.

Young, E. Deitrick, L., Tinkler, T., Meschen, C., Strawser, C., Funderburk, T., \& Abruzzo, T. (2020). Unprecedented disruption: COVID-19 impact on San Diego nonprofits. Nonprofit Sector Issues and Trends, 5. Retrieved from https://digital. sandiego.edu/npi-npissues/5

Zhu, X. (2014). Mandate versus championship: Vertical government intervention and diffusion of innovation in public services in authoritarian China. Public Management Review, 16(1), $117-139$.

Zolner, K., Compeau, L. D., Jones, J. M., \& Munger, J. (2010). Consumers' perceptions of nonprofit solicitations: Some preliminary evidence on framing and price effects. Journal of Nonprofit and Public Sector Marketing, 22(1), 1-13.

Publisher's Note Springer Nature remains neutral with regard to jurisdictional claims in published maps and institutional affiliations. 